\title{
Narrative Review: Nutrient Deficiencies in Adults and Children with Treated and Untreated Celiac Disease
}

\author{
Johanna M. Kreutz ${ }^{1}$, Marlou P. M. Adriaanse ${ }^{1}$, Elisabeth M. C. van der Ploeg ${ }^{2}$ and \\ Anita C. E. Vreugdenhil 1,* \\ 1 Department of Paediatrics and NUTRIM School of Nutrition and Translational Research in Metabolism, \\ Maastricht University Medical Centre, P. Debyelaan 25, 6229 HX Maastricht, The Netherlands; \\ johanna.kreutz@mumc.nl (J.M.K.); marlouadriaanse@hotmail.com (M.P.M.A.) \\ 2 Department of Dietetics, Maastricht University Medical Centre, P. Debyelaan 25, 6229 HX Maastricht, \\ The Netherlands liesbeth.vander.ploeg@mumc.nl \\ * Correspondence: a.vreugdenhil@mumc.nl; Tel.: +31-433875284
}

Received: 3 January 2020; Accepted: 13 February 2020; Published: 15 February 2020

\begin{abstract}
Nutrient deficiencies are well recognized as secondary consequences of celiac disease (CD) and closely related to the clinical presentation of affected patients. Despite their clinical significance, consensus is lacking on the pattern and frequency of nutrient deficiencies in CD, the usefulness of their assessment at the time of diagnosis and during follow-up. This review aims to provide an overview of nutrient deficiencies among pediatric and adult $C D$ patients at diagnosis and on a gluten-free diet (GFD), and their potential causes in CD. Secondly, we review their impact on CD management strategies including the potential of nutrient supplementation. A search of Medline, Pubmed and Embase until January 2019 was performed. Despite a high variability between the reported deficiencies, we noted that nutrient deficiencies occur frequently in children and adults with $\mathrm{CD}$ at diagnosis and during treatment with a GFD. Both inadequate dietary intake and/or diminished uptake due to intestinal dysfunction contribute to nutrient deficiencies. Most deficiencies can be restored with (long-term) treatment with a GFD and/or supplementation. However, some of them persist while others may become even more prominent during GFD. Our results indicate a lack of comprehensive evidence on the clinical efficacy of nutrient supplementation in CD management highlighting the need for further studies.
\end{abstract}

Keywords: celiac disease; gluten free diet; nutrient deficiencies; nutritional status; supplementation

\section{Introduction}

Celiac disease $(\mathrm{CD})$ is a common immune-enteropathy triggered by dietary gluten in genetically susceptible individuals [1]. In CD, the immunologic response to gluten peptides causes histological abnormalities in the small intestine. These histological aberrations such as villous atrophy reduce the functional capacity of the intestine [1]. A clinically relevant consequence is malabsorption resulting in an increased risk for nutritional deficiencies. These deficiencies can contribute to clinically important comorbidities such as anemia, osteoporosis and depression [2-4]. Nutritional deficiencies do not only play a role at the time of diagnosis, but also during treatment with a gluten-free diet (GFD).

The functional absorptive surface of the intestine in $\mathrm{CD}$ is expected to restore after treatment with a GFD, thereby reestablishing nutrient absorption. However, studies reveal that full histological recovery requires long-term treatment, especially in adult patients. This makes CD patients prone to nutrient deficiencies in the first period after initiation of a GFD, even when strictly adhering to the diet [5-8]. Another complicating factor that may trigger development of deficiencies while treating the disease 
with a GFD is the diet itself. Withdrawing gluten-containing foods from the diet and substituting them with cereals that are less rich in nutrients may lead to a nutritional imbalance contributing to an overall impaired nutrient status [9-11]. Currently, it is unclear which types of nutrient deficiencies are frequently present in CD patients at diagnosis and during treatment with a GFD. Moreover, there is a lack of knowledge on the clinical relevance of nutrient deficiencies and hence the potential impact of nutrient supplementation on the clinical outcome in $\mathrm{CD}$. To answer the main research question that forms the basis of this narrative review, we reviewed the published scientific evidence for nutrient deficiencies in pediatric and adult CD patients at diagnosis and during treatment with a GFD. Moreover, the review provides an appraisal of underlying causes of deficiencies and the clinical relevance of nutrient supplementation. Currently, the clinical impact of nutrient deficiencies and the effectiveness of their treatment are currently poorly defined. Besides, the assessment of nutrient deficiencies can be executed by different approaches, including measuring the values of individual nutrients in blood or urine, or by indirect evaluation of putative clinical consequences of deficiencies. Both of the latter approaches are addressed in this review. Finally, the review aims to evaluate whether the currently available evidence is of sufficient quality to provide recommendations for clinical practice.

\section{Materials and Methods}

For this narrative literature review, as defined by Grant et al., a search of Medline, Pubmed and Embase from 1960 until January 2019 was performed to identify potentially relevant publications [12]. The following search terms were used to search in titles and abstracts using "All fields", as well as MeSH terms when available: 'celiac disease', 'coeliac disease', 'nutrient status', 'dietary intake', 'vitamins', 'minerals', 'nutrients', 'gluten-free diet', 'histology', and 'histological recovery'. Additionally, a search with relevant nutrients was conducted including the search terms 'iron', 'ferritin', 'vitamin D', 'vitamin B6', 'vitamin B12', 'calcium', 'folic acid', 'zinc', 'magnesium'. The search was limited to studies in the English language and full-text availability. This approach resulted in a total of 8478 articles for potential inclusion in this review. The search was not narrowed down further, to make sure as many eligible articles as possible were included in this overview. All potentially relevant original articles were screened for inclusion by two researchers in a step-wise approach; first, based on title, then on screening of the abstracts, and then by full-text screening of the remaining articles. Reference lists from the selected articles were also screened manually for relevant publications. The cited articles were selected based on the relevancy to the review objectives. Included were original studies on histological recovery in celiac patients on a GFD; nutrient intake of celiac patients; and nutrient deficiencies in untreated or treated celiac patients. As there is currently no clear consensus on the definition of nutrient deficiencies and how these should be evaluated, studies were included that measured serum nutrient values. Furthermore literature describing the link between nutrient levels and associated symptoms and comorbidities in CD were added to provide a general overview. Articles describing nutrient deficiencies were only included when they reported either the percentage or total number of patients with a nutrient deficiency. An appraisal of the quality of the studies was conducted to select articles of high quality which were summarized in the results of this review. The tables report the percentages of patients or of a reference population with nutrient levels below reference point and nutrient intake below recommendation (Tables 1 and 2 respectively). For both the reference values for nutrient concentrations and reference values for recommended nutrient intake, the values chosen by the individual studies were used, meaning that the cut-off values vary between studies. Furthermore, this entails that no distinction was made in the severity of the nutritional deficit. This means, that the reported percentage of patients with a deficiency include those with severe deficiencies as well as sub-optimal values below the cut-off value. No selection was made based on the technique chosen to measure nutrient values and an overview of the selected methods was included when reported by the authors (see Supplementary Table S1). 
Only recent studies, not older than 15 years, were included in the tables. Furthermore, the study population had to be well defined with sound confirmation of $C D$ diagnosis, as well as the moment of assessment, specifically differentiating between the moment of CD diagnosis and assessment of follow-up. Only those articles were selected that presented the results in a way that they could be extracted for this review. This included a clear differentiation between groups and definition of the moment of measurements. Furthermore, the results had to provide either percentages or numbers of subjects with nutrient deficiencies or insufficient intake of certain nutrients. Consequentially, articles only providing mean or median values of nutrient levels or nutrient intake within the groups were excluded. Single-case reports were not included. Level of evidence was assessed according to the 2009 Oxford Centre for Evidence-Based Medicine (OCEBM) $[13,14]$. The evidence level could be graded down based on the researchers' assessment of study quality and relevance and could be graded up in case of a large or very large effect size. An overview of all studies included in Tables 1 and 2 is provided in the Supplementary Material of this review. The overview includes subject characteristics and demographics of each study, as well as outcome parameters and details on the information provided by the authors concerning chosen diagnostic tests chosen and cut-off values for nutrient assessment. Lastly, the level of evidence was provided according to the 2009 OCEBM (see Supplementary Table S1). Due to the small number of recent, high-quality publications on several nutrient values that met all the aforementioned criteria, other studies that did not meet these criteria were included in the review as well. These studies were included as the best available evidence and were highlighted within the text and tables as being of lower quality.

\section{Nutritional Deficiencies in Celiac Disease at Diagnosis and on a Gluten-Free Diet}

An overview of the most important nutrient and mineral deficiencies reported in $\mathrm{CD}$ at diagnosis and on a GFD are summarized in Table 1. Percentages of nutrient deficiency in healthy reference populations are mentioned in Table 1 as well. The majority (69\%) of the studies summarized in this review were conducted in Europe, 13\% in North America, and 9\% in India, the remaining studies being conducted in Israel, Australia and South America. Half of the studies were conducted prospectively, while the other half were mainly retrospective chart reviews or cross-sectional studies (see Supplementary Table S1). 
Table 1. Overview of nutrient deficiencies at diagnosis and during follow-up on a gluten-free diet.

\begin{tabular}{|c|c|c|c|c|}
\hline Nutrient & $\begin{array}{l}\text { Percentage of Untreated CD } \\
\text { Patients with Circulating Levels } \\
\text { below Reference Value (\%) }\end{array}$ & $\begin{array}{c}\text { Percentage of Treated CD Patients with } \\
\text { Circulating Levels below Reference Value (\%) } \\
\text { Short Term Follow-up, }<2 \text { years on a GFD (Time } \\
\text { on GFD) }\end{array}$ & $\begin{array}{c}\text { Percentage of Treated CD Patients with } \\
\text { Circulating Levels below Reference Value (\%) } \\
\text { Long Term Follow-up, >2 years on a GFD (Time } \\
\text { on GFD) }\end{array}$ & $\begin{array}{c}\text { Percentage of Individuals in the } \\
\text { General Reference Population } \\
\text { with Circulating Levels below } \\
\text { Reference Value (\%) }\end{array}$ \\
\hline \multicolumn{5}{|c|}{ Adults } \\
\hline $\begin{array}{l}\text { Vitamin D } \\
(25(\mathrm{OH}) \mathrm{D})\end{array}$ & $5 \%-88 \%[18,20,25-28]$ & $\begin{array}{c}50 \% \\
\text { (1 year) [29] * }\end{array}$ & $\begin{array}{c}7.6 \%(5 \text { years }) \\
0 \% \text { (mean } 4 \text { years for men, } 9 \text { years for women) } \\
{[29,30]^{*}}\end{array}$ & $50 \%[25]$ \\
\hline Vitamin B12 & $5 \%-19 \%[16-18,20,22,32]$ & data not available & $\begin{array}{c}0 \% \\
(8-12 \text { years) }[33]\end{array}$ & $7 \%-17 \%[18,23]$ \\
\hline $\begin{array}{c}\text { Vitamin B6 } \\
\text { (vitamin B6/Plasma pyridoxal } 5 \text { phosphatase) }\end{array}$ & $15 \%[18]$ & data not available & $\begin{array}{c}37 \% \\
(8-12 \text { years) }[33]\end{array}$ & $0 \%[18]$ \\
\hline $\begin{array}{c}\text { Folic acid } \\
\text { (folic acid/folate) }\end{array}$ & $11 \%-75 \%[15-20,22,23,31,32]$ & data not available & $\begin{array}{c}20 \% \\
(8-40 \text { years) }[33] \text { * }\end{array}$ & $4 \%-14 \%[18,23,32]$ \\
\hline Zinc & $67 \%[18]$ & $\begin{array}{c}30 \% \\
(1 \text { year) }[24]\end{array}$ & $\begin{array}{c}20 \% \\
\text { (range } 8 \text { months }-7 \text { years) }[34] \text { * }\end{array}$ & data not available \\
\hline Magnesium & $13 \%-17 \%[35,36]$ * & data not available & data not available & data not available \\
\hline $\begin{array}{c}\text { Iron } \\
\text { (iron/ferritin) }\end{array}$ & $12 \%-82 \%[22,23,37-39]$ & $\begin{array}{l}\text { Serum iron: } 5 \%-10 \% \\
\text { Serum ferritin: } 21 \%-27 \% \\
\text { (6 months- } 2 \text { years) }[38,39]\end{array}$ & $\begin{array}{l}\text { Serum iron: } 4 \%-8 \% \\
\text { (3-5.5 years) }[38]\end{array}$ & $17 \%[23]$ \\
\hline Vitamin D & $0 \%-70 \%[25,38-42]$ & $\begin{array}{c}0 \%-57 \% \\
(6 \text { months }-2 \text { years) }[38-41]\end{array}$ & $\begin{array}{c}12 \%-25 \% \\
(2-5.5 \text { years) }[38]\end{array}$ & $4 \%-30 \%[25,40,42]$ \\
\hline Calcium & $0 \%-41 \%[37,38,40,43-46]$ & $\begin{array}{c}0 \% \\
(6 \text { months- } 2 \text { years) }[38,40]\end{array}$ & $\begin{array}{c}0 \% \\
(3 \text { years- }-5.5 \text { years) }[38]\end{array}$ & $0 \%[40]$ \\
\hline Vitamin B12 & $1 \%-14 \%[22,23,37,38]$ & $\begin{array}{c}0 \%-1 \% \\
(6 \text { months- } 2 \text { years) }[38,39]\end{array}$ & $\begin{array}{c}0 \% \\
(3-5.5 \text { years) }[38]\end{array}$ & $7 \%[23]$ \\
\hline Vitamin B6 & data not available & data not available & data not available & data not available \\
\hline Folic acid & $14 \%-31 \%[22,23,37,38]$ & $\begin{array}{c}0 \%-3 \% \\
(1-2 \text { years) }[38]\end{array}$ & $\begin{array}{c}0 \% \\
(3-5.5 \text { years) }[38]\end{array}$ & $14 \%[23]$ \\
\hline Zinc & $19 \%-72 \%[37,39,47]$ & $\begin{array}{c}16 \%-18 \% \\
(6-18 \text { months) [39] }\end{array}$ & data not available & data not available \\
\hline Magnesium & $7 \%-11 \%[40,48]$ & data not available & $\begin{array}{c}4 \% \\
\text { (11 years; range 3-17) [48] }\end{array}$ & $0 \%[40]$ \\
\hline
\end{tabular}

Overview of reported percentages of adult and pediatric CD patients with a nutrient deficiency at the moment of diagnosis and during follow-up with a GFD. All reported values are summarized in ranges, with the corresponding studies referenced in square brackets. The duration of GFD is mentioned in brackets in columns three and four. * Studies that did not meet quality criteria were only included if no other eligible article existed for that nutrient level and are marked by an asterisk. Abbreviations: celiac disease (CD); gluten-free diet (GFD). 


\subsection{Nutritional Deficiencies at Moment of Diagnosis in Untreated Celiac Disease}

Twenty-nine studies that evaluated nutritional deficiencies in $\mathrm{CD}$ at diagnosis were identified, only 15 of which describe nutritional status in children. The most frequently described deficiencies in CD patients at diagnosis are of iron, vitamin D, calcium, vitamin B12, folic acid and zinc. Presence of iron deficiency was described in $6 \%-82 \%$ of adult patients and in $12 \%-82 \%$ of pediatric patients newly diagnosed with CD [15-23,37-39]. Iron status has been well researched in regard to CD and the results presented here were obtained from twelve different study populations.

Vitamin B12 (cobalamin) deficiency has been reported in 5\%-19\% of untreated CD patients [16-18,20,22,23,32,37]. Folic acid deficiency (vitamin B9) has been described in $11 \%$ up to, as many as $75 \%$ of adults with untreated CD and $14 \%-31 \%$ of children $[15-20,22,23,31,32,37,38]$.

The prevalence of deficiencies in several micronutrients in $\mathrm{CD}$ is unclear. This is due to lack of scientific evidence or high variety between studies. This is the case in vitamin B6 deficiency, for instance, which has recently only been studied in two adult but no pediatric CD cohorts. A recent study from Wierdsma et al. showed that vitamin B6 deficiency was present in 15\% of untreated adult CD patients but not in controls [18]. In contrast, other studies reported similar vitamin B6 levels in adult CD patients compared to healthy controls [49].

Vitamin D levels were demonstrated to be low in $5 \%-88 \%$ of untreated adult patients, and in $0 \%-70 \%$ of untreated pediatric patients $[18,25-27,40-42,45]$. Circulating levels of calcium were described to be low in $0 \%-26 \%$ of untreated adults and $0 \%-41 \%$ of pediatric patients $[17,19,37,40,45,46]$. The only prospective case-control study of good quality investigating hypocalcemia was conducted by Zanchi et al. which found a high prevalence of $40.7 \%$ of hypocalcemia at diagnosis in pediatric CD patients, compared to $0 \%$ in controls [40]. Similarly, the evidence of higher quality available for vitamin $\mathrm{D}$ levels also indicates a high prevalence of vitamin $\mathrm{D}$ deficiency in pediatric $\mathrm{CD}$ patients. Tokgöz et al. found a prevalence of vitamin D deficiency in $92.4 \%$ of CD patients compared to $18 \%$ in controls. This difference becomes even more profound when separately investigating vitamin D insufficiency (levels below $30 \mathrm{ng} / \mathrm{mL}$ ) which was present in $61.5 \%$ of CD patients and merely $4 \%$ of healthy controls [42].

Next to calcium, deficiencies in other minerals and elements are associated with $C D$, although literature reporting on these is particularly scarce. Magnesium deficiency was reported in $7 \%-11 \%$ of untreated pediatric CD patients [40,48]. Magnesium deficiency in untreated adult CD patients has only been reported in two studies that did not meet the criteria for the quality assessment, being published longer than 20 years ago, indicating a prevalence of magnesium deficiency in $13 \%-17 \%[35,36]$. Zinc deficiency has been found in $67 \%$ of untreated adult patients. Notably, all three studies reporting zinc levels in pediatric patients with active disease have found levels below the reference value in more than half of the patients, and a prospective randomized controlled trial conducted by Rawal et al. even found zinc deficiency to be present in more than $70 \%$ of patients $[37,47,50]$.

Taken together, nutrient deficiencies are highly prevalent at time of $\mathrm{CD}$ diagnosis in the pediatric and adult population, although there is a variance in reported fractions of nutrient deficiencies. Importantly, not only routinely measured nutrients such as iron and vitamin B12 are deficient, but also less recognized and studied nutrients such as zinc appear to be deficient frequently in patients with active CD.

\subsection{Nutritional Deficiencies While on a Gluten-Free Diet in Treated Celiac Disease}

After diagnosis and institution of a GFD, restoring the nutrient status and maintaining adequate nutrient intake in $\mathrm{CD}$ patients remains a challenge. Studies reported that mean micronutrient levels increase in adult patients within one year of gluten elimination [17,23,32]. However, the velocity of this increase can vary, and an increase in nutrient concentrations does not always lead to full normalization. The rate of normalization as well as the time period necessary for nutrient levels to restore is of clinical importance, as it can impact health and disease outcomes in the short and long term. The selected studies mainly chose a time period of 6 to 12 months after institution of the GFD as indicators for short-term follow-up. Based on these results, few conclusions can be drawn on 
the time period necessary for recovery of nutrient deficiencies after diagnosis (see Table 1). When studying the prevalence of nutritional deficiencies in $\mathrm{CD}$ after diagnosis, these can be grouped into three categories: nutrient deficiencies that generally fully normalize during treatment; deficiencies that are more prevalent during follow-up than at the moment of diagnosis, and lastly, nutrients of which levels generally improve, yet not to the extent seen in a healthy reference population.

Nutrients that appear to be generally corrected in CD patients on a GFD are vitamin B12, folic acid, calcium and magnesium (see Table 1). Vitamin B12 deficiency has been described in $0 \%$ of treated adult CD patients by Vilppula et al. [17].

A GFD seems to also improve or even normalize folic acid levels in CD patients $[17,23,24,30,32,51,52]$. Folic acid deficiency in adults with CD on a GFD has not been reported in a study that met the quality assessment of this review, but it has been described in studies with a moderate quality. Hallert et al. reported low serum folate levels in $20 \%$ of adult CD patients on a 10-year GFD with a normalized intestinal mucosa in a study that met all criteria of our quality assessment except for the year of publication which was more than 15 years ago [33]. The prevalence of folic acid deficiency in treated children with CD has been studied in one recent publication that met our quality assessment. Wessels et al. describe a low prevalence of $0 \%-3 \%$ in their retrospective pediatric cohort on a GFD [38].

Likewise, resolution of calcium deficiency and to a lesser degree vitamin D levels was observed after institution of a GFD in most cases, which was confirmed in the study by Zanchi et al. with a high level of evidence $[17,29,30,38-41,53]$. Calcium levels have been described to be normal in all treated children with CD, while vitamin D was low in $0 \%-57 \%$ of children and in $0 \%-50 \%$ of adult patients on a GFD $[29,30,38-41,53]$. Next to the quality of the studies, it is important to consider that vitamin D levels especially are also low in the general population, when interpreting these results $[25,40]$. Additionally, the studies report nutrient deficiencies in the serum and do not take distribution and storage in the body into account. In the case of calcium and vitamin D for example, bone mineral density (BMD) and dental health are also a measure for total calcium in the body. Comorbidities associated with CD-related nutrient deficiencies are reviewed in the next section of this review.

The effect of a GFD on magnesium levels is scarcely studied, yet appears to result in normalization of magnesium levels. Rujner et al. showed that the frequency of magnesium deficiency in treated adult CD patients (median 11 years on a GFD) was similar to that in untreated patients and controls [48]. In children, magnesium deficiency has been described in $4 \%$ of celiac patients on a GFD for 11 years [48].

In contrast to the aforementioned nutrient deficiencies that generally restore, other deficiencies might be even more prevalent on a GFD compared to the moment of diagnosis. Vitamin B6 deficiency might be an example of this. Studies reporting vitamin B6 levels in CD are, however, scarce and no study was available that met the inclusion criterion of this review which only included studies not older than 15 years. In a Swedish patient cohort of moderate quality published in 2002, low vitamin B6 plasma levels were found in 37\% of adult CD patients on a long-term GFD, despite a recovered intestinal mucosa and dietary intake meeting recommendations [33].

Lastly, a considerable group of micronutrient imbalances improve, yet remain a prevalent problem on a GFD, iron deficiency being a chief example. Iron deficiency was described in $14 \%-41 \%$ of adult celiac patients on a GFD [54]. Strikingly, little evidence is available on the prevalence of iron deficiency in pediatric patients on a GFD and even less on the potential clinical implications in this regard. This should be given more attention, considering that iron deficiency anemia (IDA) is one of the most prevalent extra-intestinal manifestations of CD at diagnosis [21,38,55]. Adherence to a GFD does appear to reduce the prevalence and severity of IDA and increases serum iron and ferritin, although repletion of iron stores may take a prolonged time after healing of the intestinal mucosa $[17,24,43,51,56,57]$. In adult $C D$ patients, the degree of histological recovery was associated with an increase in serum hemoglobin concentrations and impaired hemoglobin levels were evident in patients with incomplete mucosal recovery [57]. In pediatric CD patients on a GFD, the severity of villous atrophy correlated inversely with serum ferritin level, although no correlation with other hematological parameters was 
found [58]. Popov et al. showed a significant increase in mean serum ferritin concentration in pediatric CD patients after GFD in a retrospective chart review [59]. These findings were independent of the use of iron supplementation. Likewise, Wessels et al. showed a decrease in the proportion of pediatric CD patients with an iron deficiency after institution of a GFD [38,59]. In summary, iron deficiency appears to restore in a substantial proportion of CD patients after institution of the GFD. However, iron deficiency is still present in a considerable fraction of CD patients on a GFD.

In a similar way to iron deficiency, zinc deficiency appears to not improve sufficiently during CD treatment. A GFD has been shown to reduce zinc deficiency from a proportion of up to $72 \%$ of untreated CD patients to $16 \%-30 \%$ of patients on a GFD presenting with this deficiency $[18,24,34,37,39,47,60]$. Although zinc appears to restore in most patients, zinc deficiency was still found in $20 \%-30 \%$ of adult CD patients on a GFD $[24,34]$.

When looking at hyperhomocysteinemia, controversial results have been found, and it is unclear whether this is generally corrected or remains a relevant consequence of CD even on a GFD. Studies on the occurrence of hyperhomocysteinemia showed a decrease of homocysteine levels after starting a GFD [32,49]. Dickey et al. reported normal levels in CD patients with recovered villous atrophy, while patients with persistent villous atrophy tended to have mildly elevated homocysteine levels [49]. However, Hallert et al. showed raised homocysteine levels in $17 \%$ of adult CD patients on a strict GFD for several years [33,61]. Also, levels of serum folate, vitamin B12 and vitamin B6 correlated inversely with homocysteine levels in CD patients [32,33,49,61]. Yet, Hadithi et al. reported that the presence and severity of CD were determinants of homocysteine levels, independent of measured B vitamin status [62].

\subsection{Comorbidities Potentially Related to Nutrient Deficiencies in Celiac Disease}

Nutrient deficiencies in CD can be the cause or a contributing factor to several symptoms and comorbidities associated with CD (see Figure 1). These, symptoms and comorbidities can serve as indicators for nutrient deficiencies in the long and short term.

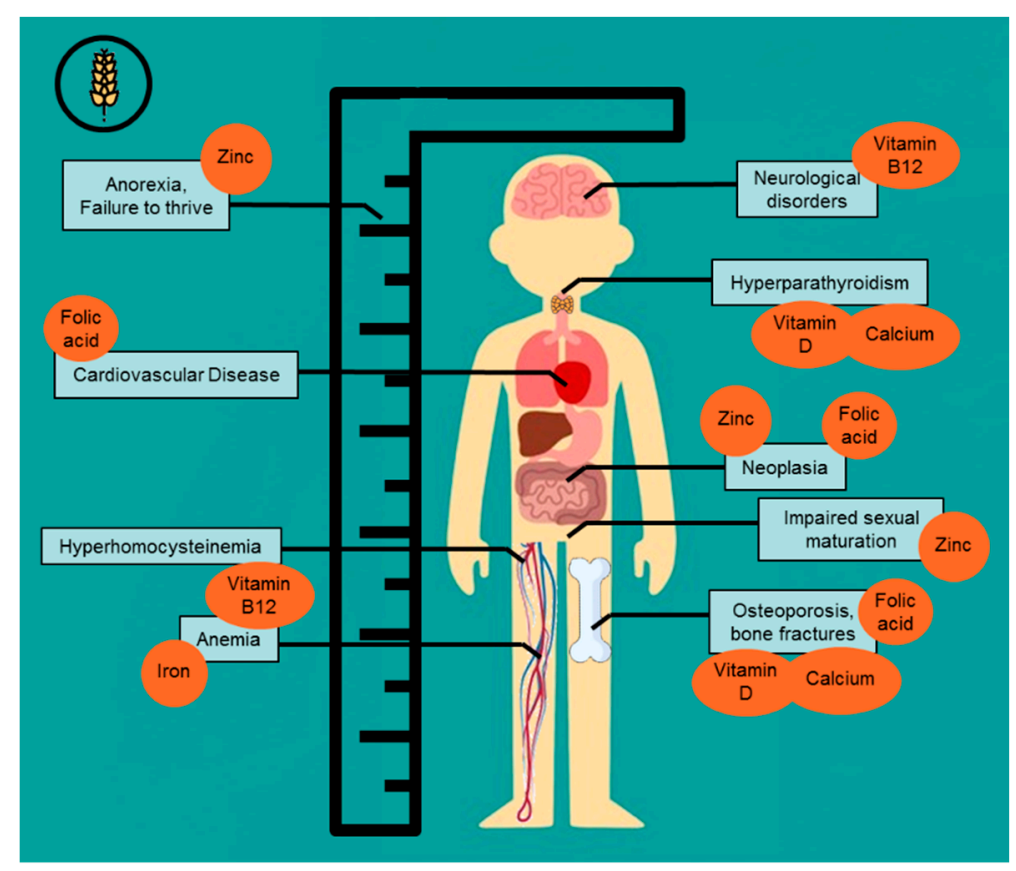

Figure 1. Comorbidities associated with nutrient deficiencies often found in celiac disease.

IDA is one of the most prevalent extra-intestinal manifestations of CD at diagnosis [21,55]. IDA can cause symptoms associated with CD such as fatigue, headaches and decreased exercise tolerance. 
Anemia in $\mathrm{CD}$ has further shown to be associated with greater disease severity and slower histological recovery in response to the GFD [63-65].

Other plausible causes of anemia in CD include vitamin B12 and/or folate deficiency, two nutrients essential in DNA synthesis. Deficiencies in these nutrients can limit DNA synthesis and result in megaloblastic anemia [66,67]. Vitamin B6 is important in hemoglobin formation, hence low levels of vitamin B6 can also contribute to the development of anemia in CD [68]. Therefore, anemia and its resulting symptoms can be a useful indicator for the importance of nutrient deficiencies in CD.

Both vitamin B12 and folate, as well as vitamin B6 are also essential in the conversion of the harmful homocysteine. B vitamin deficiencies can therefore cause hyperhomocysteinemia in CD [66,67,69-71]. Consequentially, increased severity of celiac lesions is associated with higher homocysteine levels [62]. Aberrant homocysteine levels are related to an increased risk for venous thromboembolism, vascular disease, osteoporosis and adverse pregnancy outcomes [72-74].

Vitamin B12 deficiency has further been held responsible for several neurological symptoms which have been described in CD [66]. Folic acid deficiency has also been linked to a wide range of neurological disorders and conditions as diverse as neoplasia, cardiovascular disease and osteoporosis [67].

Other complications related to $\mathrm{CD}$ involve bone health, which is closely related to the nutritional status especially of calcium and vitamin D [75]. Impaired bone health is highly prevalent in children and adults at diagnosis of $C D$, even in individuals with mild enteropathy (without villous atrophy) [43,44,76-85]. In adult onset CD, a GFD generally improves but rarely normalizes BMD and the serious impact of this is shown in studies examining fracture risk [51,86]. Jafri et al. showed that fracture risk is increased in $\mathrm{CD}$ at diagnosis and during long term follow-up and a meta-analysis by Heikkilä et al. confirmed this increased risk for fractures in patients with CD $[87,88]$.

In pediatric $\mathrm{CD}$, the evidence on recovery of bone health and its impact on growth and long-term complications is more divergent. A strict GFD promotes an increase in BMD that may lead to complete recovery of bone mineralization within 1-2 years [40,43-45,77-82]. For instance, Mora et al. found that BMD and bone area normalized within a year of treatment in pediatric CD patients [78,79]. However, Kalayci et al. found that one year of strict GFD was insufficient for osteopenia to resolve in a substantial number of pediatric patients and suggests that BMD should be monitored in these children [78]. The influence that this could have on bone health in later life is uncertain. Moreover, the long term consequences of an initial impaired bone health and low calcium and vitamin D levels during childhood, regardless of its restoration, are not clear.

Two other important minerals that can cause complications in CD patients when deficient, are zinc and magnesium. As summarized earlier, zinc deficiency is highly prevalent at diagnosis in pediatric and adult CD patient and seems to restore insufficiently when on a GFD $[18,24,34-37,43,47,50,89]$.

Zinc is an essential trace element involved in numerous enzymatic reactions, biochemical functions and immune responses, and is required for growth and cellular function [90-92]. Zinc deficiency can alter protein synthesis, and in the absence of zinc growth retardation and impairment of sexual maturation occurs, which makes it particularly important for the pediatric CD population [92,93]. Classical presenting symptoms of CD such as anorexia and failure to thrive have therefore been linked to zinc deficiency [94]. Altuntas et al., found that zinc deficiency was present in more than half of the patients presenting with short stature that were diagnosed with CD in a pediatric population [50]. And although zinc deficiency appears to remain a relevant problem after institution of a GFD, little is known about the consequences of transient or persistent zinc deficiency in CD $[47,89,94]$.

\subsection{Role of Nutrient Supplementation in Celiac Disease Management}

Overall, only few studies have systematically assessed the impact of nutrient supplementation as an additional therapy next to a GFD in CD. Some studies have suggested that nutrient supplementation may positively influence recovery, whereas others describe no difference between patients receiving supplementation and patients who do not. 
Foods rich in iron can be recommended in patients on a GFD, and supplements may be prescribed in clinical practice [9-11]. However, two prospective studies published in 1996 and 2003 found that even after iron supplementation for up to one year in pediatric $C D$ patients, a significant number continued to have iron deficiency [43,58]. Additionally, a retrospective chart review showed that improvement of iron status in pediatric CD patients on a GFD was unrelated to the intake of supplementation [59]. It must, however, be noted that the use of supplementation was based on parent-reported medication history.

In a study of vitamin status in adult CD patients after long-term treatment, circulating vitamin B12 as well as B6 levels were poorly correlated with dietary intake [33]. By contrast, vitamin B supplementation (folic acid, cyanocobalamin and pyridoxine) in CD patients on a long-term GFD has been shown to be effective in increasing serum vitamin B12 and B6 levels as well as serum folic acid levels [61,62]. Median serum levels were significantly higher in CD patients on B vitamin supplementation compared to both CD patients not using supplementation and healthy controls [62]. However, the role of each individual vitamin has not been established.

Supplementation of vitamin B12 in patients on a GFD may be effective to prevent neurological complications associated with CD [95]. An increase in serum folic acid due to supplementation has been shown to be clinically relevant, since 6 months of supplementation improved anxiety and depressed mood in patients with longstanding treated CD [61].

Complications of poor bone health have far-reaching effects on a lifelong scale. Therefore additional measures improving bone health or at least preventing further bone loss in CD patients on a GFD might be beneficial. Calcium and vitamin D supplementation is considered a possible treatment option. However, neither vitamin D supplementation alone nor combined calcium and vitamin D supplementation for one year in adult CD patients provided additional benefit to the GFD with respect to BMD $[96,97]$. In children and adolescents with CD on a GFD, two years of combined calcium and vitamin D supplementation was reported to increase BMD, but levels did not normalize to those measured in healthy controls [98].

Supplementation in a methodologically sound randomized controlled trial of zinc for four weeks in newly diagnosed pediatric $C D$ patients was not effective in increasing zinc levels compared to children who started a GFD without supplementation [47]. To our knowledge, the effect of supplementation of magnesium in CD patients has not been studied.

\section{Causes of Nutritional Deficiencies in Celiac Disease}

As shown above, nutritional imbalances are present in a substantial number of patients diagnosed with CD [99-101]. Nutrient deficiencies result from an imbalance between nutrient supply and biological need. In $\mathrm{CD}$, nutrient supply can be insufficient due to impaired uptake on the one hand, and as a consequence of inadequate nutrient intake when on a GFD on the other hand. Impaired uptake is the main factor of nutrient deficiencies at diagnosis and becomes less important after histological recovery. After institution of a GFD, recovery of the small intestine occurs in most CD patients, making insufficient nutrient intake the factor most likely to contributing to nutrient imbalances, due to possible nutritional inadequacy of the GFD itself (see Table 2) [102-106]. 
Table 2. Overview of dietary intake of nutrients on a gluten-free diet in celiac disease patients and reference populations.

\begin{tabular}{|c|c|c|}
\hline Nutrient & $\begin{array}{l}\text { Percentage of CD Patients with } \\
\text { Nutrient Intake below } \\
\text { Recommendations (\%) }\end{array}$ & $\begin{array}{l}\text { Percentage of Individuals in the } \\
\text { General Reference Population } \\
\text { with Nutrient Intake below } \\
\text { Recommendations (\%) }\end{array}$ \\
\hline \multicolumn{3}{|c|}{ Adults } \\
\hline Iron & $46 \%-54 \%[52,99,101,104,107]$ & $14 \%[52,99]$ \\
\hline Vitamin D & $53 \%-100 \%[99,107,108]$ & data not available \\
\hline Calcium & $12 \%-78 \%[99,101,104,107-110]$ & $6 \%-29 \%[52,99]$ \\
\hline Vitamin B12 & $10 \%-61 \%[99,107,111]$ & $1 \%-65 \%[99,111]$ \\
\hline Vitamin B6 & $33 \%[111]$ & $17 \%[111]$ \\
\hline Folic acid & $35 \%-100 \%[54,101,107,110-112]$ & $3 \%-100 \%[52,99,111]$ \\
\hline Zinc & $11 \%-58 \%[52,101,107,108,110]$ & $30 \%[52]$ \\
\hline Magnesium & $28 \%-50 \%[52,101]$ & $29 \%[52]$ \\
\hline \multicolumn{3}{|c|}{ Children } \\
\hline Iron & $8 \%$ [113] & $43 \%-79 \%[100,110]^{*}$ \\
\hline Vitamin D & $68 \%[113]$ & data not available \\
\hline Calcium & $8 \%-54 \%[48,113]$ & $86 \%[110]^{*}$ \\
\hline Vitamin B12 & $0 \%$ [113] & data not available \\
\hline Vitamin B6 & $8 \%$ [113] & data not available \\
\hline Folic acid & $80 \%$ [110] & $57 \%[110] *$ \\
\hline Zinc & $40 \%[110]$ & $43 \%[110]^{*}$ \\
\hline Magnesium & $29 \%-76 \%[48,113]$ & data not available \\
\hline
\end{tabular}

Overview of reported percentages of adults and children with $\mathrm{CD}$ and of general reference populations with nutrient intake below the recommended levels. All reported values are summarized in ranges, with the corresponding studies referenced in square brackets. ${ }^{*}$ Studies that did not meet the quality criteria were only included if no other eligible article existed for the intake of that nutrient and are marked by an asterisk. Abbreviations: celiac disease (CD).

\subsection{Impaired Absorption DUE to Compromised Intestinal Epithelial Function}

Absorption of macro- and micronutrients occurs in the small intestine, the site specifically affected in CD. Therefore, nutritional deficiencies due to diminished absorptive capacity are expected in active CD. Villous architecture and absorptive cells (enterocytes) are severely damaged and reduced in number in CD patients. Additionally, many enzymes necessary for digestion and absorption of nutrients are depleted or dysfunctioning, particularly brush border enzymes like the disaccharidases maltase, isomaltase, and lactase [114]. The disease affects the proximal small intestine and extends distally for a variable length in a more or less continuous fashion, with more severe damage in the proximal than in the distal part [54]. Consequently, mucosal impairment in CD at diagnosis may result in malabsorption of macro- and micronutrients, and studies show that more pronounced mucosal damage leads to increasing nutritional deficiencies $[19,115,116]$.

The proximal small intestine is the site of absorption for iron, folate, and calcium [117]. Minerals and elements including zinc and magnesium are also mainly absorbed in the proximal small intestine, explaining why their levels may be low in CD patients [34]. Deficiencies in these nutrients can be explained by reduced absorptive capacity as well as reduced enzyme function in the affected proximal small intestine.

Iron deficiency in untreated celiac patients is primarily caused by malabsorption due to loss of duodenal enterocytes. This results in a reduction of absorptive surface, as well as decreased 
amounts of the brush border enzyme ferrireductase, necessary for iron transport across the cellular membrane $[117,118]$. Moreover, enterocytes have an iron-storage capacity themselves which is directly affected by villous atrophy $[117,118]$. Although it has been previously suggested that gastrointestinal blood loss might also contribute to iron deficiency, recent studies suggest gastrointestinal bleeding to be uncommon in CD [119,120].

Diminished enzyme count and function also play a role in folic acid deficiency in untreated CD, since dietary folate, in the form of polyglutamates, is absorbed and cleaved to the monoglutamate form in the duodenum and jejunum, which are affected in CD [121].

Another example highlighting the complex causal cascade involved in development of nutrient deficiencies in CD is calcium. Potential factors involved are: loss of villous surface area, binding of calcium to unabsorbed fatty acids in the intestinal lumen, impairment of the active intestinal calcium transport mechanism due to depletion of vitamin D in enterocytes, and decreased dietary calcium and vitamin D intake secondary to concomitant lactase deficiency [122-124]. This shows that, for example, vitamin D deficiency can in turn enhance or cause other deficiencies, for example of calcium and magnesium. The small intestine normally absorbs up to $50 \%$ of magnesium intake, in part under the influence of active vitamin D [125,126].

More distal parts of the small intestine, jejunum and proximal ileum are responsible for absorption of carbohydrates, fat, vitamin B6 and fat-soluble vitamins (A, D, E, and K), while vitamins B12 absorption occurs in the terminal ileum [127]. Given the relative absence of villous atrophy in the (terminal) ileum, the mechanisms responsible for vitamin B12 deficiency in CD are unclear. In the ileum, vitamin B12 is absorbed bound to intrinsic factor, while a small portion is absorbed via passive diffusion along the entire small intestine. Hypothesized causes for vitamin B12 deficiency in CD include decreased secretion of gastric acid, dysfunctioning intrinsic factor, autoimmune gastritis, bacterial overgrowth or decreased efficiency of mixing with transfer factors $[66,95,128]$.

\subsection{Histological Recovery on a Gluten-Free Diet}

Strict adherence to a GFD has classically been assumed to result in complete recovery of the intestinal mucosa and its absorptive function [129]. Indeed, elimination of gluten from the diet improves villous architecture and reduces the number of intraepithelial lymphocytes (IEL) [129]. However, despite its simple appearance, it is difficult to adhere to a strict GFD in the Western world where wheat is widely present in food (see Section 4.3). Inadvertent gluten intake may contribute to delayed mucosal recovery, as well as contamination of gluten-free products. Nevertheless, studies have shown that complete histological normalization is not always achieved in adult patients even when they maintain a strict GFD [5,7,129-132]. Currently, there is no full agreement on this topic. Therefore, insufficient histological recovery in CD is a potential reason for inadequate restoration or development of nutrient deficiencies even on a GFD and the mechanisms described above remain relevant in explaining causes of deficiencies in treated CD (see Section 4.1). In contrast, full histological recovery is almost always found in pediatric CD patients with good compliance to the GFD $[8,133]$. Moreover, the progress of histological recovery seems faster in children than adult CD patients $[8,133]$.

Therefore, reduced absorptive capacity appears to be a less important cause of nutrient deficiencies in pediatric CD patients on a GFD [134]. Several studies performed to evaluate the histological recovery in adult CD patients after initiation of a GFD report a minority of CD patients achieving complete recovery of the intestinal mucosa within the first years of treatment. Long-term studies suggest that villous atrophy persists in $4 \%-79 \%$ of adult CD patients despite gluten elimination for an average of 8 years [5,7,129-131].

The wide range in reported histological recovery rates may be caused by the lack of prospective studies (selection bias), mixed adult and pediatric populations, various degrees of dietary strictness, a variable duration of gluten elimination prior to follow-up biopsies, and different definitions of mucosal and villous recovery. Nevertheless, authors agree that recovery of the celiac mucosa requires long-term treatment, especially in adult patients $[6,7,129,130]$. 
The slow and incomplete intestinal recovery in CD patients on a GFD might contribute to nutrient deficiencies. For instance, the degree of histological damage in $C D$ patients has been shown to correlate with the severity of iron deficiency at time of diagnosis $[18,19,24,27]$. In addition, folic acid levels are generally depressed in patients with severe villous atrophy compared to patients with milder lesions. Although most studies reported no significant differences in vitamin B12 concentrations between patients with partial or (sub)total villous atrophy, others showed that vitamin B12 levels tended to correlate with the severity of the intestinal lesions $[23,24,27,95,116,128]$. However, no correlation has been found to date between the severity of the small intestinal lesion and vitamin D, B6, calcium, magnesium and zinc levels in celiac patients.

\subsection{Nutrient Imbalance associated with a Gluten-Free Diet}

Historically, the treatment of $\mathrm{CD}$ has focused on the avoidance of gluten-containing food and less importance has been devoted to the nutritional quality of the GFD [99]. However, maintaining a nutritionally adequate diet on a GFD requires effort and attention and insufficient dietary intake of nutrients is an important contributing factor to nutritional deficiencies in $\mathrm{CD}$. The grains and gluten-containing products excluded in a GFD, are a major source of iron, dietary fiber, B vitamins and iodine, and contribute substantially to the energy and protein content of a normal diet. Their elimination from the diet inevitably alter the macro- and micronutrient composition of a GFD [33,52,56,99,106,135].

Rice, corn and potatoes are widely used as natural substitutes of gluten-containing grains but are generally less nutrient dense. Moreover, processed gluten-free products are often of lower quality and poorer nutritional value compared with their gluten-containing equivalents [9-11,106]. A number of nutrient-dense grains, including the pseudo-cereals buckwheat, quinoa and amaranth, represent a safe alternative concerning gluten absence while improving the variety and palatability of the GFD, and are a good source of carbohydrates, protein, dietary fiber, vitamins, minerals, and polyunsaturated fatty acids $[136,137]$.

On a macronutrient level, several studies suggest that a GFD is characterized by lower intake of (complex) carbohydrates and fibers, with subsequent higher protein and fat consumption $[30,33,52,56,99,108,113,135,138]$. The altered macronutrient dietary patterns can have negative consequences. For example, poor dietary fiber intake can increase the risk of other chronic diseases [99,101,113,135,139]. Additionally, a rise in body mass index (BMI) and increased prevalence of metabolic syndrome has been observed in CD patients after initiation of a GFD [140,141].

\section{Intake of Micronutrients}

Gluten-free cereal products generally contain inferior amounts of iron, folate and B vitamins compared to the products they are intended to replace, contributing to a lower intake of these nutrients by CD patients on a GFD [9-11]. Adult CD patients on a GFD failed to achieve the recommended daily amount of iron intake in $46 \%-54 \%$ of cases (see Table 2) [52,99,101,104,113,135,138]. In contrast, other studies suggested that iron intake is similar or even higher compared to healthy controls and Ohlund et al. found that merely $8 \%$ of pediatric CD patients failed to meet the recommended intake for iron $[52,99,101,135,138]$. Likewise, the intake of folic acid in adult CD patients is generally below recommendations (in 35\%-98\% of patients), but was shown to be similar or higher compared to the reference population in most studies [33,49,52,99,101,113,138]. In children with CD, folic acid intake has been shown to meet recommendations, similar to controls [138]. Additionally, the correlation between dietary intake and plasma levels of folate was found to be poor [33]. Vitamin B6 intake has been reported to be below recommendations in $33 \%$ of adults, which was significantly higher compared to $17 \%$ in controls in a cross sectional case-control study by Valente et al., and in $8 \%$ of pediatric patients adhering to a GFD [111,113]. A low nutrient density of the other B vitamins thiamine (B1), riboflavin (B2) and niacin (B3) has been found in the diet of treated pediatric CD patients compared to healthy controls [113]. 
Surprisingly, the intake of nutrients not present in cereal products appears to be low as well in patients on a GFD. Animal products (meat and dairy) represent the only dietary source of vitamin B12 and are not restricted in a GFD. Therefore, the intake of vitamin B12 in CD patients on a GFD appears to meet recommendations, both in adults and children $[33,113,138]$. However, Kinsey et al. showed a low mean daily vitamin B12 intake in 10\% of patients aged above 65 [99]. The intake of vitamin $\mathrm{D}$ has been suggested to be below recommendations in both pediatric patients $(68 \%$ with a poor intake) and in adult patients $(53 \%-100 \%)$ on a GFD, even below the generally low intake in healthy subjects $[99,113,138]$.

Although minerals are located in the germ of grains and are not expected to be completely lost during the refining process, there is evidence that suggests low intake of minerals in CD patients on gluten elimination. Due to secondary lactose intolerance, calcium consumption might be low in CD patients. The intake of calcium in CD patients adhering to a GFD failed to achieve recommendations in $12 \%-78 \%$ of adults and in $8 \%-54 \%$ of children, although it has been shown to be similar or above intake-levels in reported reference populations $[48,52,99,101,104,107-110,113]$. Low calcium intake has a negative effect on BMD, which can already be impaired at time of CD diagnosis. Patients on a GFD also failed to achieve the recommended daily amount of magnesium intake in $29 \%-76 \%$ of children and in $28 \%-50 \%$ of adults, in line with the general population $[48,52,101,113,138]$. Furthermore, zinc intake was reported to be below recommendations in $11 \%-58 \%$ of adult CD patients adhering to a GFD, in line with intake in healthy adults in the reference population $[52,101,108]$. Pseudo-cereals contain higher amounts of minerals compared to other gluten-free cereals such as rice and maize and, therefore, provide a good alternative for CD patients [142].

Nutrient inadequacies in processed gluten-free products and incorrect dietary choices may contribute to inadequate nutrient intake identified in CD patients adhering to a GFD. In line with this, nutrient imbalances were more evident in children with strict compliance to a GFD than non-compliant patients [100]. A different choice of grains has the potential to improve the nutrient profile of the diet for individuals with $C D$, but attention must be paid to the complete dietary pattern [137]. Taken together, attention is required to the dietary shortcomings of micronutrients in $\mathrm{CD}$ patients adhering to a GFD.

\section{Discussion}

The current review of the available literature indicates that both newly diagnosed and $C D$ patients following a GFD frequently exhibit nutrient deficiencies. Second, nutrient deficiencies are associated with short- and long-term manifestations and complications of CD [2-4,49]. However, the clinical impact of nutrient deficiencies and their modulation by treatment in $C D$ patients are still unclear based on the available literature. Our current review identifies a high degree of variation between reports and a deficit in scientific evidence supporting a consistent role of nutrient deficiencies in CD on several levels. For example, no high-quality studies were identified that assessed deficiencies of iron, vitamin $\mathrm{D}$, vitamin B12, folic acid, zinc or magnesium status in adult CD patients on a GFD. In general, after the analysis of the level of evidence of the reports reviewed in this work, only low-to moderate-level studies and practically no high-quality, high-level evidence studies were available. As a result, the evidence base is not strong enough to pronounce sound recommendations on CD management concerning nutrient status. Therefore, we suggest evaluating nutrient levels at the time of diagnosis as well as regularly during follow-up, until further research provides the evidence base necessary to generate more detailed recommendations. The results of this review show the importance of a nutritionally balanced dietary pattern as a part of CD management that can still lead to clinical improvement in most patients. Health providers should focus not only on gluten avoidance, but also on a balanced diet with respect to macro- and micronutrients in all CD patients. Early education of patients by a skilled dietitian with expert knowledge in $\mathrm{CD}$ is needed to address the achievement of adequate (micro) nutrient intake in patients on a GFD. Naturally gluten-free foods should be recommended as these have a higher nutritional value in terms of protein and fiber provision and vitamin content as opposed 
to the commercially purified gluten-free products [9-11]. Fortification of gluten-free foods needs to be considered and should at least match the micronutrient content of the foods they intend to replace. Targeted supplementation based on laboratory findings or a multivitamin and mineral supplement could be beneficial to the health status and recovery of individual CD patients, although care should be taken to avoid hypervitaminosis. Thus, vitamin B12 as well as folic acid supplementation have been shown to be clinically relevant in preventing or reducing neurological and psychological symptoms in CD patients. In children and adolescents, vitamin $\mathrm{D}$ and calcium supplementation are of particular importance to improve BMD. Interestingly, most studies evaluating the role of dietary supplements in CD management mainly focus on the restoration of blood levels as opposed to the effects on clinical consequences of nutrient deficiencies. However, if clinically relevant outcomes are investigated, the focus lies largely on long-term effects of nutrient supplementation on parameters such as BMD. Thus, short-term adverse effects of nutrient deficiencies are not taken into account. IDA and iron deficiency for example, may improve on a GFD regardless of the use of iron supplements, but may improve faster in patients using supplementation. A prolonged duration of recovery could have potentially harmful effects on the patients' health and/or psychosocial well-being. A prolonged period of IDA in pediatric CD patients could, for instance, result in a longer period of fatigue and weakness, impairing school performance and social life. In adult CD patients, this burden could also have an additional societal impact when resulting symptoms lead to reduced work performance or prolonged sick leave [143,144]. Taking this into account, the time it takes for nutrient deficiencies to restore after initiation of GFD treatment should be of interest in future studies. Moreover, efforts should be made to generate more evidence supporting sound recommendations regarding the effects of treatment and monitoring of $C D$ patients in which a nutrient deficiency or a clinical consequence of deficiency has been detected.

As mentioned above, certain limitations of this review's methodology should be taken into account. These limitations, combined with several weaknesses in the current literature, especially concerning the assessment of nutrient deficiencies, should be addressed and summarized. This is not only of great importance for interpretation of the presented overview, but also to provide recommendations concerning future research efforts. Although this narrative review has not been constructed as a systematic review, an extensive literature search of three databases has been conducted aiming to give as comprehensive an overview as possible. Nevertheless, this review is not a complete representation of all studies, but rather provides an overview of the current state of knowledge. High-quality studies were also included in this review, however, due to their scarcity some studies of lesser quality were considered in order to provide a general overview (see Supplementary Table S1). Through conducting the literature search and selection by two investigators and broad screening for eligible articles, we aimed to minimize the risk of selection bias, but nonetheless we still present a narrative review.

A lack of consensus could be identified concerning several methodological aspects. This results in high variability in conducted studies concerning patient selection, chosen cut-off points for nutrient values and varying quality of assays measuring nutrient levels. Therefore, we present the reported percentages of patients with micronutrient values below the reference points, as chosen by the researchers of the respective studies. A uniform, clinically relevant cut-off value was thus not selected, as this can be controversial regarding several nutrients, for instance concerning vitamin $\mathrm{D}$ concentrations [145-147]. Another relevant point of concern is whether micronutrient levels measured in the blood (serum or plasma) are an accurate indicator of the overall status of a certain micronutrient in the entire body. This relates, for example, to zinc and magnesium measurements. It was suggested that other biomarkers in the blood could be a more accurate indicator of zinc status in the body [148]. Similarly, there are conflicting views on the use of magnesium levels in blood or urine as an assessment for magnesium status [149]. Notably, few studies make a distinction in the severity of nutrient deficiencies, but rather only report on the number of patients not meeting the lower cut-off value (see Supplementary Table S1) [40-42]. In order to truly evaluate the scope of the problem of nutrient deficiencies in $C D$, future studies might separately report on patients with sub-optimal nutrient values and patients with severe deficiencies. Overall, these shortcomings reflect general limitations 
of the current literature on this topic and could be viewed as an important outcome of this review. A consensus on these methodological issues should thus be achieved before studies assessing the subject matter elaborated upon in this review are executed.

\section{Summary and Conclusions}

Both newly diagnosed CD patients and patients adhering to a GFD frequently demonstrate nutrient deficiencies which can have important clinical consequences. Nutrient deficiencies with known clinical relevance in CD patients include iron, vitamin $\mathrm{D}$, folic acid, zinc and calcium at the time of diagnosis and iron, vitamin D, vitamin B6 and zinc during treatment with GFD.

In newly diagnosed $C D$ patients these deficiencies may reflect the loss of absorptive surface area as well as functional capacity. Following the elimination of gluten from the diet, improvement in small intestinal histology occurs gradually, especially in adult patients. Consequently, recovery of nutrient deficiencies after diagnosis takes time. Nevertheless, even during long-term GFD treatment in CD patients with biopsy-proven remission, these patients may still show nutrient deficiencies due to insufficient nutrient intake.

Several known comorbidities, e.g. osteoporosis, anemia and neurological symptoms, are possible indicators of the impact that impaired nutritional status can have on $C D$ patients. In pediatric $C D$ patients, growth or impaired sexual maturation can be consequences that highlight the potential impact of impaired nutritional status in this patient group. Consequentially, assessment of nutritional status should be a part of both CD diagnosis and during follow-up. Additionally, dietary education for $\mathrm{CD}$ patients focusing not only on gluten elimination, but also the need to balance dietary patterns is important and should receive more attention.

Evidence on the benefit of nutrient supplementation on mucosal healing, correction of nutrient deficiencies or recovery from comorbidities associated with CD is inconclusive. While vitamin B12 and folic acid supplementation appear beneficial, no evidence was found supporting favorable effects of calcium and vitamin D supplementation on decreased BMD in CD.

This review, although providing evidence for the relevance of nutrient status in $\mathrm{CD}$ at diagnosis and during treatment with a GFD, shows a noteworthy lack of high-quality evidence and a high degree of variability in the current literature regarding several relevant aspects. This concerns especially the lack of research in pediatric CD patients on a GFD and the consequences of impaired nutritional status on child development. The latter undoubtedly represents an important aspect in clinical care of these pediatric $\mathrm{CD}$ patients.

The causes of an impaired nutrient status in $C D$ are currently only poorly understood. As improvement of nutritional status is of great importance for patients, further studies are warranted with comprehensive assessment of nutrient status in untreated and, even more importantly, treated CD patients are warranted. Studies should differentiate between adult and pediatric study populations and evaluate the need for optimal timing and dosing of supplementation as part of CD management. Prospective cohort studies would be expedient to further investigate the prevalence of certain nutrient deficiencies, their resulting health complications, and the potential role of nutrient supplements. It is of importance that future cohort studies are conducted on a multinational scale. This would not only account for differences between patient groups with different dietary habits, but also for patient groups that receive different types of medical care, from general practitioners and primary care facilities to specialized tertiary centers. Furthermore, researchers should pay more attention to the methodological aspects of assessing nutrient deficiencies, specifically regarding the type of measurement and appropriate reference values, clearly distinguishing between patients with sub-optimal nutrient levels and those with severe deficiencies. This will enable a more accurate evaluation of the scope of the problem and the clinical efficacy of treatment in the future. Long-term prospective studies could also provide evidence on the time it takes for nutritional deficiencies to recover and the factors influencing this process. This may shed light on the question whether we should strive to achieve a more rapid recovery of nutrient levels in $\mathrm{CD}$ patients after diagnosis. It could 
further clarify the matter if this can be achieved through attention to diet alone, or through addition of nutrient supplementation. In order to conduct valuable research addressing nutrient status in $\mathrm{CD}$, it is crucial to reach a consensus on cut-off values of nutrient levels as well as the adequate techniques that should be used to assess them. When investigating the causes for the occurrence of certain deficiencies, the addition of a group of subjects (controls) following a GFD that do not have $\mathrm{CD}$ could be of additional value. This is currently more feasible, as GFD is becoming increasingly popular in healthy individuals without $\mathrm{CD}$ or in patients with non-celiac gluten sensitivity. This will yield important further knowledge to improve overall management of $C D$. The goal of this should be to relieve symptoms, recover the intestinal mucosa, and reverse the consequences of CD-related malabsorption, while enabling patients to secure a nutritionally adequate GFD.

Supplementary Materials: The following are available online at http://www.mdpi.com/2072-6643/12/2/500/s1: Table S1: Overview of studies included in Tables 1 and 2, describing nutrient deficiencies in celiac disease patients with active and treated CD or nutrient intake in CD patients on a gluten-free diet.

Author Contributions: conceptualization, A.C.E.V. and M.P.M.A.; formal analysis, J.M.K., M.P.M.A., E.M.C.v.d.P.; data curation, A.C.E.V., J.M.K., M.P.M.A., E.M.C.v.d.P.; writing-original draft preparation, J.M.K. and M.P.M.A.; writing-review and editing, A.C.E.V., J.M.K., M.P.M.A., E.M.C.v.d.P.; visualization, J.M.K.; supervision, A.C.E.V.; All authors have read and agreed to the published version of the manuscript.

Funding: This research received no external funding.

Conflicts of Interest: The authors declare no conflict of interest.

\section{References}

1. Green, P.H.; Cellier, C. Celiac disease. N. Engl. J. Med. 2007, 357, 1731-1743. [CrossRef]

2. Halfdanarson, T.R.; Litzow, M.R.; Murray, J.A. Hematologic manifestations of celiac disease. Blood 2007, 109, 412-421. [CrossRef]

3. Corazza, G.R.; Di Stefano, M.; Maurino, E.; Bai, J.C. Bones in coeliac disease: Diagnosis and treatment. Best Pract. Res. Clin. Gastroenterol. 2005, 19, 453-465. [CrossRef]

4. Bushara, K.O. Neurologic presentation of celiac disease. Gastroenterology 2005, 128, S92-S97. [CrossRef]

5. Ciacci, C.; Cirillo, M.; Cavallaro, R.; Mazzacca, G. Long-term follow-up of celiac adults on gluten-free diet: Prevalence and correlates of intestinal damage. Digestion 2002, 66, 178-185. [CrossRef]

6. Hutchinson, J.M.; West, N.P.; Robins, G.G.; Howdle, P.D. Long-term histological follow-up of people with coeliac disease in a UK teaching hospital. QJM Mon. J. Assoc. Physicians 2010, 103, 511-517. [CrossRef]

7. Lee, S.K.; Lo, W.; Memeo, L.; Rotterdam, H.; Green, P.H. Duodenal histology in patients with celiac disease after treatment with a gluten-free diet. Gastrointest. Endosc. 2003, 57, 187-191. [CrossRef]

8. Wahab, P.J.; Meijer, J.W.; Mulder, C.J. Histologic follow-up of people with celiac disease on a gluten-free diet: Slow and incomplete recovery. Am. J. Clin. Pathol. 2002, 118, 459-463. [CrossRef]

9. Thompson, T. Folate, iron, and dietary fiber contents of the gluten-free diet. J. Am. Diet. Assoc. 2000, 100, 1389-1396. [CrossRef]

10. Thompson, T. Thiamin, riboflavin, and niacin contents of the gluten-free diet: Is there cause for concern? J. Am. Diet. Assoc. 1999, 99, 858-862. [CrossRef]

11. Miranda, J.; Lasa, A.; Bustamante, M.A.; Churruca, I.; Simon, E. Nutritional differences between a gluten-free diet and a diet containing equivalent products with gluten. Plant Foods Hum. Nutr. 2014, 69, 182-187. [CrossRef]

12. Grant, M.J.; Booth, A. A typology of reviews: An analysis of 14 review types and associated methodologies. Health Inf. Libr. J. 2009, 26, 91-108. [CrossRef]

13. OCEBM Levels of Evidence Working Group; Howick, J.; Chalmers, I.; Glasziou, P.; Greenhalgh, T.; Heneghan, C.; Liberati, A.; Moschetti, I.; Phillips, B.; Thornton, H.; et al. The Oxford 2011 Levels of Evidence; University of Oxford: Oxford, UK, 2011.

14. Howick, J.; Phillips, B.; Ball, C.; Sackett, D.; Badenoch, D.; Straus, S.; Haynes, B.; Dawes, M. Oxford Centre for Evidence-based Medicine-Levels of Evidence (March 2009); University of Oxford: Oxford, UK, 2009.

15. Tikkakoski, S.; Savilahti, E.; Kolho, K.L. Undiagnosed coeliac disease and nutritional deficiencies in adults screened in primary health care. Scand. J. Gastroenterol. 2007, 42, 60-65. [CrossRef] 
16. Harper, J.W.; Holleran, S.F.; Ramakrishnan, R.; Bhagat, G.; Green, P.H. Anemia in celiac disease is multifactorial in etiology. Am. J. Hematol. 2007, 82, 996-1000. [CrossRef]

17. Vilppula, A.; Kaukinen, K.; Luostarinen, L.; Krekela, I.; Patrikainen, H.; Valve, R.; Luostarinen, M.; Laurila, K.; Maki, M.; Collin, P. Clinical benefit of gluten-free diet in screen-detected older celiac disease patients. BMC Gastroenterol. 2011, 11, 136. [CrossRef]

18. Wierdsma, N.J.; van Bokhorst-de van der Schueren, M.A.; Berkenpas, M.; Mulder, C.J.; van Bodegraven, A.A. Vitamin and mineral deficiencies are highly prevalent in newly diagnosed celiac disease patients. Nutrients 2013, 5, 3975-3992. [CrossRef]

19. Zanini, B.; Caselani, F.; Magni, A.; Turini, D.; Ferraresi, A.; Lanzarotto, F.; Villanacci, V.; Carabellese, N.; Ricci, C.; Lanzini, A. Celiac disease with mild enteropathy is not mild disease. Clin. Gastroenterol. Hepatol. 2013, 11, 253-258. [CrossRef]

20. Schosler, L.; Christensen, L.A.; Hvas, C.L. Symptoms and findings in adult-onset celiac disease in a historical Danish patient cohort. Scand. J. Gastroenterol. 2016, 51, 288-294. [CrossRef]

21. Sansotta, N.; Amirikian, K.; Guandalini, S.; Jericho, H. Celiac Disease Symptom Resolution: Effectiveness of the Gluten-free Diet. J. Pediatric Gastroenterol. Nutr. 2018, 66, 48-52. [CrossRef]

22. Berry, N.; Basha, J.; Varma, N.; Varma, S.; Prasad, K.K.; Vaiphei, K.; Dhaka, N.; Sinha, S.K.; Kochhar, R. Anemia in celiac disease is multifactorial in etiology: A prospective study from India. JGH Open 2018, 2, 196-200. [CrossRef]

23. Haapalahti, M.; Kulmala, P.; Karttunen, T.J.; Paajanen, L.; Laurila, K.; Maki, M.; Mykkanen, H.; Kokkonen, J. Nutritional status in adolescents and young adults with screen-detected celiac disease. J. Pediatric Gastroenterol. Nutr. 2005, 40, 566-570. [CrossRef]

24. Kemppainen, T.A.; Kosma, V.M.; Janatuinen, E.K.; Julkunen, R.J.; Pikkarainen, P.H.; Uusitupa, M.I. Nutritional status of newly diagnosed celiac disease patients before and after the institution of a celiac disease diet-association with the grade of mucosal villous atrophy. Am. J. Clin. Nutr. 1998, 67, 482-487. [CrossRef]

25. Lerner, A.; Shapira, Y.; Agmon-Levin, N.; Pacht, A.; Ben-Ami Shor, D.; Lopez, H.M.; Sanchez-Castanon, M.; Shoenfeld, Y. The clinical significance of $25 \mathrm{OH}-$ Vitamin D status in celiac disease. Clin. Rev. Allergy Immunol. 2012, 42, 322-330. [CrossRef]

26. Chakravarthi, S.D.; Jain, K.; Kochhar, R.; Bhadada, S.K.; Khandelwal, N.; Bhansali, A.; Dutta, U.; Nain, C.K.; Singh, K. Prevalence and predictors of abnormal bone mineral metabolism in recently diagnosed adult celiac patients. Indian J. Gastroenterol. 2012, 31, 165-170. [CrossRef]

27. Garcia-Manzanares, A.; Tenias, J.M.; Lucendo, A.J. Bone mineral density directly correlates with duodenal Marsh stage in newly diagnosed adult celiac patients. Scand. J. Gastroenterol. 2012, 47, 927-936. [CrossRef]

28. Posthumus, L.; Al-Toma, A. Duodenal histopathology and laboratory deficiencies related to bone metabolism in coeliac disease. Eur. J. Gastroenterol. Hepatol. 2017, 29, 897-903. [CrossRef]

29. Kemppainen, T.; Kroger, H.; Janatuinen, E.; Arnala, I.; Lamberg-Allardt, C.; Karkkainen, M.; Kosma, V.M.; Julkunen, R.; Jurvelin, J.; Alhava, E.; et al. Bone recovery after a gluten-free diet: A 5-year follow-up study. Bone 1999, 25, 355-360. [CrossRef]

30. McFarlane, X.A.; Bhalla, A.K.; Reeves, D.E.; Morgan, L.M.; Robertson, D.A. Osteoporosis in treated adult coeliac disease. Gut 1995, 36, 710-714. [CrossRef]

31. Fernandez, A.; Gonzalez, L.; de-la-Fuente, J. Coeliac disease: Clinical features in adult populations. Rev. Esp. Enferm. Dig. 2010, 102, 466-471. [CrossRef]

32. Saibeni, S.; Lecchi, A.; Meucci, G.; Cattaneo, M.; Tagliabue, L.; Rondonotti, E.; Formenti, S.; De Franchis, R.; Vecchi, M. Prevalence of hyperhomocysteinemia in adult gluten-sensitive enteropathy at diagnosis: Role of B12, folate, and genetics. Clin. Gastroenterol. Hepatol. 2005, 3, 574-580. [CrossRef]

33. Hallert, C.; Grant, C.; Grehn, S.; Granno, C.; Hulten, S.; Midhagen, G.; Strom, M.; Svensson, H.; Valdimarsson, T. Evidence of poor vitamin status in coeliac patients on a gluten-free diet for 10 years. Aliment. Pharmacol. Ther. 2002, 16, 1333-1339. [CrossRef]

34. Crofton, R.W.; Glover, S.C.; Ewen, S.W.; Aggett, P.J.; Mowat, N.A.; Mills, C.F. Zinc absorption in celiac disease and dermatitis herpetiformis: A test of small intestinal function. Am. J. Clin. Nutr. 1983, 38, 706-712. [CrossRef]

35. Boyd, S.; Collins, B.J.; Bell, P.M.; Love, A.H. Clinical presentation of coeliac disease in adult gastroenterological practice. Ulst. Med. J. 1985, 54, 140-147. 
36. Bode, S.; Gudmand-Hoyer, E. Symptoms and haematologic features in consecutive adult coeliac patients. Scand. J. Gastroenterol. 1996, 31, 54-60. [CrossRef]

37. Kuloglu, Z.; Kirsaclioglu, C.T.; Kansu, A.; Ensari, A.; Girgin, N. Celiac disease: Presentation of 109 children. Yonsei Med. J. 2009, 50, 617-623. [CrossRef]

38. Wessels, M.M.S.; van, V., II; Vriezinga, S.L.; Putter, H.; Rings, E.H.; Mearin, M.L. Complementary Serologic Investigations in Children with Celiac Disease Is Unnecessary during Follow-Up. J. Pediatrics 2016, 169, 55-60. [CrossRef]

39. Deora, V.; Aylward, N.; Sokoro, A.; El-Matary, W. Serum Vitamins and Minerals at Diagnosis and Follow-up in Children with Celiac Disease. J. Pediatric Gastroenterol. Nutr. 2017, 65, 185-189. [CrossRef]

40. Zanchi, C.; Di Leo, G.; Ronfani, L.; Martelossi, S.; Not, T.; Ventura, A. Bone metabolism in celiac disease. J. Pediatrics 2008, 153, 262-265. [CrossRef]

41. Mager, D.R.; Qiao, J.; Turner, J. Vitamin D and K status influences bone mineral density and bone accrual in children and adolescents with celiac disease. Eur. J. Clin. Nutr. 2012, 66, 488-495. [CrossRef]

42. Tokgoz, Y.; Terlemez, S.; Karul, A. Fat soluble vitamin levels in children with newly diagnosed celiac disease, a case control study. BMC Pediatr. 2018, 18, 130. [CrossRef]

43. Rea, F.; Polito, C.; Marotta, A.; Di Toro, A.; Iovene, A.; Collini, R.; Rea, L.; Sessa, G. Restoration of body composition in celiac children after one year of gluten-free diet. J. Pediatric Gastroenterol. Nutr. 1996, 23, 408-412. [CrossRef]

44. Kavak, U.S.; Yuce, A.; Kocak, N.; Demir, H.; Saltik, I.N.; Gurakan, F.; Ozen, H. Bone mineral density in children with untreated and treated celiac disease. J. Pediatric Gastroenterol. Nutr. 2003, 37, 434-436. [CrossRef]

45. Tau, C.; Mautalen, C.; De Rosa, S.; Roca, A.; Valenzuela, X. Bone mineral density in children with celiac disease. Effect of a Gluten-free diet. Eur. J. Clin. Nutr. 2006, 60, 358-363. [CrossRef]

46. Volkan, B.; Fettah, A.; Islek, A.; Kara, S.S.; Kurt, N.; Cayir, A. Bone mineral density and vitamin K status in children with celiac disease: Is there a relation? Turk. J. Gastroenterol. 2018, 29, 215-220. [CrossRef]

47. Rawal, P.; Thapa, B.R.; Prasad, R.; Prasad, K.K.; Nain, C.K.; Singh, K. Zinc supplementation to patients with celiac disease-Is it required? J. Trop. Pediatrics 2010, 56, 391-397. [CrossRef]

48. Rujner, J.; Socha, J.; Syczewska, M.; Wojtasik, A.; Kunachowicz, H.; Stolarczyk, A. Magnesium status in children and adolescents with coeliac disease without malabsorption symptoms. Clin. Nutr. 2004, 23, 1074-1079. [CrossRef]

49. Dickey, W.; Ward, M.; Whittle, C.R.; Kelly, M.T.; Pentieva, K.; Horigan, G.; Patton, S.; McNulty, H. Homocysteine and related B-vitamin status in coeliac disease: Effects of gluten exclusion and histological recovery. Scand. J. Gastroenterol. 2008, 43, 682-688. [CrossRef]

50. Altuntas, B.; Filik, B.; Ensari, A.; Zorlu, P.; Tezic, T. Can zinc deficiency be used as a marker for the diagnosis of celiac disease in Turkish children with short stature? Pediatrics Int. 2000, 42, 682-684. [CrossRef]

51. Sategna-Guidetti, C.; Grosso, S.B.; Grosso, S.; Mengozzi, G.; Aimo, G.; Zaccaria, T.; Di Stefano, M.; Isaia, G.C. The effects of 1-year gluten withdrawal on bone mass, bone metabolism and nutritional status in newly-diagnosed adult coeliac disease patients. Aliment. Pharmacol. Ther. 2000, 14, 35-43. [CrossRef]

52. Wild, D.; Robins, G.G.; Burley, V.J.; Howdle, P.D. Evidence of high sugar intake, and low fibre and mineral intake, in the gluten-free diet. Aliment. Pharmacol. Ther. 2010, 32, 573-581. [CrossRef]

53. Keaveny, A.P.; Freaney, R.; McKenna, M.J.; Masterson, J.; O’Donoghue, D.P. Bone remodeling indices and secondary hyperparathyroidism in celiac disease. Am. J. Gastroenterol. 1996, 91, 1226-1231.

54. Murray, J.A.; Rubio-Tapia, A.; Van Dyke, C.T.; Brogan, D.L.; Knipschield, M.A.; Lahr, B.; Rumalla, A.; Zinsmeister, A.R.; Gostout, C.J. Mucosal atrophy in celiac disease: Extent of involvement, correlation with clinical presentation, and response to treatment. Clin. Gastroenterol. Hepatol. 2008, 6, 186-193. [CrossRef]

55. Ferrara, M.; Coppola, L.; Coppola, A.; Capozzi, L. Iron deficiency in childhood and adolescence: Retrospective review. Hematology 2006, 11, 183-186. [CrossRef]

56. Capristo, E.; Addolorato, G.; Mingrone, G.; De Gaetano, A.; Greco, A.V.; Tataranni, P.A.; Gasbarrini, G. Changes in body composition, substrate oxidation, and resting metabolic rate in adult celiac disease patients after a 1-y gluten-free diet treatment. Am. J. Clin. Nutr. 2000, 72, 76-81. [CrossRef]

57. Annibale, B.; Severi, C.; Chistolini, A.; Antonelli, G.; Lahner, E.; Marcheggiano, A.; Iannoni, C.; Monarca, B.; Delle Fave, G. Efficacy of gluten-free diet alone on recovery from iron deficiency anemia in adult celiac patients. Am. J. Gastroenterol. 2001, 96, 132-137. [CrossRef] 
58. Kapur, G.; Patwari, A.K.; Narayan, S.; Anand, V.K. Iron supplementation in children with celiac disease. Indian J. Pediatrics 2003, 70, 955-958. [CrossRef]

59. Popov, J.; Baldawi, M.; Mbuagbaw, L.; Gould, M.; Mileski, H.; Brill, H.; Pai, N. Iron Status in Pediatric Celiac Disease: A Retrospective Chart Review. J. Pediatric Gastroenterol. Nutr. 2017. [CrossRef]

60. Hogberg, L.; Danielsson, L.; Jarleman, S.; Sundqvist, T.; Stenhammar, L. Serum zinc in small children with coeliac disease. Acta Paediatr. 2009, 98, 343-345. [CrossRef]

61. Hallert, C.; Svensson, M.; Tholstrup, J.; Hultberg, B. Clinical trial: B vitamins improve health in patients with coeliac disease living on a gluten-free diet. Aliment. Pharmacol. Ther. 2009, 29, 811-816. [CrossRef]

62. Hadithi, M.; Mulder, C.J.; Stam, F.; Azizi, J.; Crusius, J.B.; Pena, A.S.; Stehouwer, C.D.; Smulders, Y.M. Effect of B vitamin supplementation on plasma homocysteine levels in celiac disease. World J. Gastroenterol. WJG 2009, 15, 955-960. [CrossRef]

63. Saukkonen, J.; Kaukinen, K.; Koivisto, A.M.; Maki, M.; Laurila, K.; Sievanen, H.; Collin, P.; Kurppa, K. Clinical Characteristics and the Dietary Response in Celiac Disease Patients Presenting with or without Anemia. J. Clin. Gastroenterol. 2016. [CrossRef]

64. Rajalahti, T.; Repo, M.; Kivela, L.; Huhtala, H.; Maki, M.; Kaukinen, K.; Lindfors, K.; Kurppa, K. Anemia in Pediatric Celiac Disease: Association with Clinical and Histological Features and Response to Gluten-free Diet. J. Pediatric Gastroenterol. Nutr. 2017, 64, e1-e6. [CrossRef]

65. Singh, P.; Arora, S.; Makharia, G.K. Presence of anemia in patients with celiac disease suggests more severe disease. Indian J. Gastroenterol. 2014, 33, 161-164. [CrossRef]

66. O'Leary, F.; Samman, S. Vitamin B12 in health and disease. Nutrients 2010, 2, 299-316. [CrossRef]

67. Iyer, R.; Tomar, S.K. Folate: A functional food constituent. J. Food Sci. 2009, 74, R114-R122. [CrossRef]

68. Ahmad, I.; Mirza, T.; Qadeer, K.; Nazim, U.; Vaid, F.H. Vitamin B6: Deficiency diseases and methods of analysis. Pak. J. Pharm. Sci. 2013, 26, 1057-1069.

69. Wu, X.Y.; Lu, L. Vitamin B6 deficiency, genome instability and cancer. Asian Pac. J. Cancer Prev. APJCP 2012, 13, 5333-5338. [CrossRef]

70. Blom, H.J.; Smulders, Y. Overview of homocysteine and folate metabolism. With special references to cardiovascular disease and neural tube defects. J. Inherit. Metab. Dis. 2011, 34, 75-81. [CrossRef]

71. Peterson, J.C.; Spence, J.D. Vitamins and progression of atherosclerosis in hyper-homocyst(e)inaemia. Lancet 1998, 351, 263. [CrossRef]

72. Eichinger, S. Are B vitamins a risk factor for venous thromboembolism? Yes. J. Thromb. Haemost. JTH 2006, 4, 307-308. [CrossRef]

73. Bergen, N.E.; Jaddoe, V.W.; Timmermans, S.; Hofman, A.; Lindemans, J.; Russcher, H.; Raat, H.; Steegers-Theunissen, R.P.; Steegers, E.A. Homocysteine and folate concentrations in early pregnancy and the risk of adverse pregnancy outcomes: The Generation R Study. BJOG 2012, 119, 739-751. [CrossRef]

74. Tyagi, N.; Vacek, T.P.; Fleming, J.T.; Vacek, J.C.; Tyagi, S.C. Hyperhomocysteinemia decreases bone blood flow. Vasc. Health Risk Manag. 2011, 7, 31-35. [CrossRef]

75. Charoenngam, N.; Shirvani, A.; Holick, M.F. Vitamin D for skeletal and non-skeletal health: What we should know. J. Clin. Orthop. Trauma 2019, 10, 1082-1093. [CrossRef]

76. Kurppa, K.; Collin, P.; Sievanen, H.; Huhtala, H.; Maki, M.; Kaukinen, K. Gastrointestinal symptoms, quality of life and bone mineral density in mild enteropathic coeliac disease: A prospective clinical trial. Scand. J. Gastroenterol. 2010, 45, 305-314. [CrossRef]

77. Barera, G.; Beccio, S.; Proverbio, M.C.; Mora, S. Longitudinal changes in bone metabolism and bone mineral content in children with celiac disease during consumption of a gluten-free diet. Am. J. Clin. Nutr. 2004, 79, 148-154. [CrossRef]

78. Kalayci, A.G.; Kansu, A.; Girgin, N.; Kucuk, O.; Aras, G. Bone mineral density and importance of a gluten-free diet in patients with celiac disease in childhood. Pediatrics 2001, 108, E89. [CrossRef]

79. Mora, S.; Barera, G.; Beccio, S.; Menni, L.; Proverbio, M.C.; Bianchi, C.; Chiumello, G. A prospective, longitudinal study of the long-term effect of treatment on bone density in children with celiac disease. J. Pediatrics 2001, 139, 516-521. [CrossRef]

80. Mora, S.; Barera, G.; Ricotti, A.; Weber, G.; Bianchi, C.; Chiumello, G. Reversal of low bone density with a gluten-free diet in children and adolescents with celiac disease. Am. J. Clin. Nutr. 1998, 67, 477-481. [CrossRef] 
81. Barera, G.; Mora, S.; Brambilla, P.; Ricotti, A.; Menni, L.; Beccio, S.; Bianchi, C. Body composition in children with celiac disease and the effects of a gluten-free diet: A prospective case-control study. Am. J. Clin. Nutr. 2000, 72, 71-75. [CrossRef]

82. Mora, S.; Weber, G.; Barera, G.; Bellini, A.; Pasolini, D.; Prinster, C.; Bianchi, C.; Chiumello, G. Effect of gluten-free diet on bone mineral content in growing patients with celiac disease. Am. J. Clin. Nutr. 1993, 57, 224-228. [CrossRef]

83. Jatla, M.; Zemel, B.S.; Bierly, P.; Verma, R. Bone mineral content deficits of the spine and whole body in children at time of diagnosis with celiac disease. J. Pediatric Gastroenterol. Nutr. 2009, 48, 175-180. [CrossRef]

84. Corazza, G.R.; Di Sario, A.; Cecchetti, L.; Jorizzo, R.A.; Di Stefano, M.; Minguzzi, L.; Brusco, G.; Bernardi, M.; Gasbarrini, G. Influence of pattern of clinical presentation and of gluten-free diet on bone mass and metabolism in adult coeliac disease. Bone 1996, 18, 525-530. [CrossRef]

85. Kotze, L.M.; Skare, T.; Vinholi, A.; Jurkonis, L.; Nisihara, R. Impact of a gluten-free diet on bone mineral density in celiac patients. Rev. Esp. Enferm. Dig. 2016, 108, 84-88. [CrossRef]

86. Pazianas, M.; Butcher, G.P.; Subhani, J.M.; Finch, P.J.; Ang, L.; Collins, C.; Heaney, R.P.; Zaidi, M.; Maxwell, J.D. Calcium absorption and bone mineral density in celiacs after long term treatment with gluten-free diet and adequate calcium intake. Osteoporos. Int. 2005, 16, 56-63. [CrossRef]

87. Jafri, M.R.; Nordstrom, C.W.; Murray, J.A.; Van Dyke, C.T.; Dierkhising, R.A.; Zinsmeister, A.R.; Melton, L.J., III. Long-term fracture risk in patients with celiac disease: A population-based study in Olmsted County, Minnesota. Dig. Dis. Sci. 2008, 53, 964-971. [CrossRef]

88. Heikkila, K.; Pearce, J.; Maki, M.; Kaukinen, K. Celiac disease and bone fractures: A systematic review and meta-analysis. J. Clin. Endocrinol. Metab. 2015, 100, 25-34. [CrossRef]

89. Crofton, R.W.; Aggett, P.J.; Gvozdanovic, S.; Gvozdanovic, D.; Mowat, N.A.; Brunt, P.W. Zinc metabolism in celiac disease. Am. J. Clin. Nutr. 1990, 52, 379-382. [CrossRef]

90. Coleman, J.E. Zinc enzymes. Curr. Opin. Chem. Biol. 1998, 2, 222-234. [CrossRef]

91. Salgueiro, M.J.; Zubillaga, M.; Lysionek, A.; Cremaschi, G.; Goldman, C.G.; Caro, R.; De Paoli, T.; Hager, A.; Weill, R.; Boccio, J. Zinc status and immune system relationship: A review. Biol. Trace Elem. Res. 2000, 76, 193-205. [CrossRef]

92. Jeejeebhoy, K. Zinc: An essential trace element for parenteral nutrition. Gastroenterology 2009, 137, S7-S12. [CrossRef]

93. Hambidge, K.M.; Hambidge, C.; Jacobs, M.; Baum, J.D. Low levels of zinc in hair, anorexia, poor growth, and hypogeusia in children. Pediatric Res. 1972, 6, 868-874. [CrossRef]

94. Tran, C.D.; Katsikeros, R.; Manton, N.; Krebs, N.F.; Hambidge, K.M.; Butler, R.N.; Davidson, G.P. Zinc homeostasis and gut function in children with celiac disease. Am. J. Clin. Nutr. 2011, 94, 1026-1032. [CrossRef]

95. Dahele, A.; Ghosh, S. Vitamin B12 deficiency in untreated celiac disease. Am. J. Gastroenterol. 2001, 96, 745-750. [CrossRef]

96. Caraceni, M.P.; Molteni, N.; Bardella, M.T.; Ortolani, S.; Nogara, A.; Bianchi, P.A. Bone and mineral metabolism in adult celiac disease. Am. J. Gastroenterol. 1988, 83, 274-277.

97. Mautalen, C.; Gonzalez, D.; Mazure, R.; Vazquez, H.; Lorenzetti, M.P.; Maurino, E.; Niveloni, S.; Pedreira, S.; Smecuol, E.; Boerr, L.A.; et al. Effect of treatment on bone mass, mineral metabolism, and body composition in untreated celiac disease patients. Am. J. Gastroenterol. 1997, 92, 313-318.

98. Muzzo, S.; Burrows, R.; Burgueño, M.; Ríos, G.; Bergenfreid, C.; Chavez, E.; Leiva, L. Effect of calcium and vitamin D supplementation on bone mineral density of celiac children. Nutr. Rev. 2000, 20, 1241-1247. [CrossRef]

99. Kinsey, L.; Burden, S.T.; Bannerman, E. A dietary survey to determine if patients with coeliac disease are meeting current healthy eating guidelines and how their diet compares to that of the British general population. Eur. J. Clin. Nutr. 2008, 62, 1333-1342. [CrossRef]

100. Mariani, P.; Viti, M.G.; Montuori, M.; La Vecchia, A.; Cipolletta, E.; Calvani, L.; Bonamico, M. The gluten-free diet: A nutritional risk factor for adolescents with celiac disease? J. Pediatric Gastroenterol. Nutr. 1998, 27, 519-523. [CrossRef]

101. Shepherd, S.J.; Gibson, P.R. Nutritional inadequacies of the gluten-free diet in both recently-diagnosed and long-term patients with coeliac disease. J. Hum. Nutr. Diet. 2013, 26, 349-358. [CrossRef] 
102. Fry, L.; Madden, A.M.; Fallaize, R. An investigation into the nutritional composition and cost of gluten-free versus regular food products in the UK. J. Hum. Nutr. Diet. 2018, 31, 108-120. [CrossRef]

103. Newberry, C.; McKnight, L.; Sarav, M.; Pickett-Blakely, O. Going Gluten Free: The History and Nutritional Implications of Today's Most Popular Diet. Curr. Gastroenterol. Rep. 2017, 19, 54. [CrossRef]

104. Thompson, T.; Dennis, M.; Higgins, L.A.; Lee, A.R.; Sharrett, M.K. Gluten-free diet survey: Are Americans with coeliac disease consuming recommended amounts of fibre, iron, calcium and grain foods? J. Hum. Nutr. Diet. 2005, 18, 163-169. [CrossRef]

105. Sue, A.; Dehlsen, K.; Ooi, C.Y. Paediatric Patients with Coeliac Disease on a Gluten-Free Diet: Nutritional Adequacy and Macro- and Micronutrient Imbalances. Curr. Gastroenterol. Rep. 2018, 20, 2. [CrossRef]

106. Larretxi, I.; Simon, E.; Benjumea, L.; Miranda, J.; Bustamante, M.A.; Lasa, A.; Eizaguirre, F.J.; Churruca, I. Gluten-free-rendered products contribute to imbalanced diets in children and adolescents with celiac disease. Eur. J. Nutr. 2019, 58, 775-783. [CrossRef]

107. Mijatov, M.A.; Micetic-Turk, D. Dietary Intake in Adult Female Coeliac Disease Patients in Slovenia: PREHRANSKI VNOS ODRASLIH BOLNIC S CELIAKIJO V SLOVENIJI. Zdr. Varst. 2016, 55, 86-93. [CrossRef]

108. Grehn, S.; Fridell, K.; Killiecreutz, M.; Hallert, C. Dietary habits of Swedish adult coeliac patients treated by a gluten-free diet for 10 years. Scand. J. Nutr. 2001, 45, 178-182. [CrossRef]

109. Collins, B.J.; Bell, P.M.; Thomson, J.M.; Fee, D.B.; Wilson, E.A.; Love, A.H. Dietary history and nutritional state in treated coeliac patients. J. R. Soc. Med. 1986, 79, 206-209. [CrossRef]

110. Pham-Short, A.; Donaghue, K.C.; Ambler, G.; Garnett, S.; Craig, M.E. Greater postprandial glucose excursions and inadequate nutrient intake in youth with type 1 diabetes and celiac disease. Sci. Rep. 2017, 7, 45286. [CrossRef]

111. Valente, F.X.; Campos Tdo, N.; Moraes, L.F.; Hermsdorff, H.H.; Cardoso Lde, M.; Pinheiro-Sant'Ana, H.M.; Gilberti, F.A.; Peluzio Mdo, C. B vitamins related to homocysteine metabolism in adults celiac disease patients: A cross-sectional study. Nutr. J. 2015, 14, 110. [CrossRef]

112. Bottaro, G.; Cataldo, F.; Rotolo, N.; Spina, M.; Corazza, G.R. The clinical pattern of subclinical/silent celiac disease: An analysis on 1026 consecutive cases. Am. J. Gastroenterol. 1999, 94, 691-696. [CrossRef]

113. Ohlund, K.; Olsson, C.; Hernell, O.; Ohlund, I. Dietary shortcomings in children on a gluten-free diet. J. Hum. Nutr. Diet. 2010, 23, 294-300. [CrossRef]

114. Prasad, K.K.; Thapa, B.R.; Nain, C.K.; Sharma, A.K.; Singh, K. Brush border enzyme activities in relation to histological lesion in pediatric celiac disease. J. Gastroenterol. Hepatol. 2008, 23, e348-e352. [CrossRef]

115. Jameson, S. Coeliac disease, insulin-like growth factor, bone mineral density, and zinc. Scand. J. Gastroenterol. 2000, 35, 894-896. [CrossRef]

116. Arikan, C.; Zihni, C.; Cakir, M.; Alkanat, M.; Aydogdu, S. Morphometric analysis of small-bowel mucosa in Turkish children with celiac disease and relationship with the clinical presentation and laboratory findings. Dig. Dis. Sci. 2007, 52, 2133-2139. [CrossRef]

117. Andrews, N.C.; Schmidt, P.J. Iron homeostasis. Annu. Rev. Physiol. 2007, 69, 69-85. [CrossRef]

118. Wang, J.; Pantopoulos, K. Regulation of cellular iron metabolism. Biochem. J. 2011, 434, 365-381. [CrossRef]

119. Logan, R.F. Men and postmenopausal women with iron deficiency had increased risk for gastrointestinal malignancy. ACP J. Club 2003, 138, 80. [CrossRef]

120. Mant, M.J.; Bain, V.G.; Maguire, C.G.; Murland, K.; Yacyshyn, B.R. Prevalence of occult gastrointestinal bleeding in celiac disease. Clin. Gastroenterol. Hepatol. 2006, 4, 451-454. [CrossRef]

121. Said, H.M. Intestinal absorption of water-soluble vitamins in health and disease. Biochem. J. 2011, 437, 357-372. [CrossRef]

122. Molteni, N.; Bardella, M.T.; Vezzoli, G.; Pozzoli, E.; Bianchi, P. Intestinal calcium absorption as shown by stable strontium test in celiac disease before and after gluten-free diet. Am. J. Gastroenterol. 1995, 90, 2025-2028.

123. Pistorius, L.R.; Sweidan, W.H.; Purdie, D.W.; Steel, S.A.; Howey, S.; Bennett, J.R.; Sutton, D.R. Coeliac disease and bone mineral density in adult female patients. Gut 1995, 37, 639-642. [CrossRef]

124. Staun, M.; Jarnum, S. Measurement of the 10,000-molecular weight calcium-binding protein in small-intestinal biopsy specimens from patients with malabsorption syndromes. Scand. J. Gastroenterol. 1988, 23, 827-832. [CrossRef] 
125. Graham, L.A.; Caesar, J.J.; Burgen, A.S. Gastrointestinal absorption and excretion of Mg 28 in man. Metab. Clin. Exp. 1960, 9, 646-659.

126. Musso, C.G. Magnesium metabolism in health and disease. Int. Urol. Nephrol. 2009, 41, 357-362. [CrossRef]

127. Said, H.M. Recent advances in carrier-mediated intestinal absorption of water-soluble vitamins. Annu. Rev. Physiol. 2004, 66, 419-446. [CrossRef]

128. Dickey, W. Low serum vitamin B12 is common in coeliac disease and is not due to autoimmune gastritis. Eur. J. Gastroenterol. Hepatol. 2002, 14, 425-427. [CrossRef]

129. Haere, P.; Hoie, O.; Schulz, T.; Schonhardt, I.; Raki, M.; Lundin, K.E. Long-term mucosal recovery and healing in celiac disease is the rule-not the exception. Scand. J. Gastroenterol. 2016, 51, 1439-1446. [CrossRef]

130. Biagi, F.; Vattiato, C.; Agazzi, S.; Balduzzi, D.; Schiepatti, A.; Gobbi, P.; Corazza, G.R. A second duodenal biopsy is necessary in the follow-up of adult coeliac patients. Ann. Med. 2014, 46, 430-433. [CrossRef]

131. Laurikka, P.; Salmi, T.; Collin, P.; Huhtala, H.; Maki, M.; Kaukinen, K.; Kurppa, K. Gastrointestinal Symptoms in Celiac Disease Patients on a Long-Term Gluten-Free Diet. Nutrients 2016, 8, 429. [CrossRef]

132. Rubio-Tapia, A.; Rahim, M.W.; See, J.A.; Lahr, B.D.; Wu, T.T.; Murray, J.A. Mucosal recovery and mortality in adults with celiac disease after treatment with a gluten-free diet. Am. J. Gastroenterol. 2010, 105, 1412-1420. [CrossRef]

133. Bardella, M.T.; Velio, P.; Cesana, B.M.; Prampolini, L.; Casella, G.; Di Bella, C.; Lanzini, A.; Gambarotti, M.; Bassotti, G.; Villanacci, V. Coeliac disease: A histological follow-up study. Histopathology 2007, 50, 465-471. [CrossRef]

134. Belei, O.; Dobrescu, A.; Heredea, R.; Iacob, E.R.; David, V.; Marginean, O. Histologic recovery among children with celiac disease on a gluten-free diet. A long-term follow-up single-center experience. Arch. Med. Sci. 2018, 14, 94-100. [CrossRef]

135. Hopman, E.G.; le Cessie, S.; von Blomberg, B.M.; Mearin, M.L. Nutritional management of the gluten-free diet in young people with celiac disease in The Netherlands. J. Pediatric Gastroenterol. Nutr. 2006, 43, $102-108$. [CrossRef]

136. Alvarez-Jubete, L.; Arendt, E.K.; Gallagher, E. Nutritive value and chemical composition of pseudocereals as gluten-free ingredients. Int. J. Food Sci. Nutr. 2009, 60 (Suppl. 4), 240-257. [CrossRef]

137. Lee, A.R.; Ng, D.L.; Dave, E.; Ciaccio, E.J.; Green, P.H. The effect of substituting alternative grains in the diet on the nutritional profile of the gluten-free diet. J. Hum. Nutr. Diet. 2009, 22, 359-363. [CrossRef]

138. Zuccotti, G.; Fabiano, V.; Dilillo, D.; Picca, M.; Cravidi, C.; Brambilla, P. Intakes of nutrients in Italian children with celiac disease and the role of commercially available gluten-free products. J. Hum. Nutr. Diet. 2013, 26, 436-444. [CrossRef]

139. Anderson, J.W.; Baird, P.; Davis, R.H., Jr.; Ferreri, S.; Knudtson, M.; Koraym, A.; Waters, V.; Williams, C.L. Health benefits of dietary fiber. Nutr. Rev. 2009, 67, 188-205. [CrossRef]

140. Tortora, R.; Capone, P.; De Stefano, G.; Imperatore, N.; Gerbino, N.; Donetto, S.; Monaco, V.; Caporaso, N.; Rispo, A. Metabolic syndrome in patients with coeliac disease on a gluten-free diet. Aliment. Pharmacol. Ther. 2015, 41, 352-359. [CrossRef]

141. Kabbani, T.A.; Goldberg, A.; Kelly, C.P.; Pallav, K.; Tariq, S.; Peer, A.; Hansen, J.; Dennis, M.; Leffler, D.A. Body mass index and the risk of obesity in coeliac disease treated with the gluten-free diet. Aliment. Pharmacol. Ther. 2012, 35, 723-729. [CrossRef]

142. Dyner, L.; Drago, S.R.; Pineiro, A.; Sanchez, H.; Gonzalez, R.; Villaamil, E.; Valencia, M.E. [Composition and potential contribution of iron, calcium and zinc of bread and pasta made with wheat and amaranth flours]. Arch. Latinoam. Nutr. 2007, 57,69-77.

143. Pourhoseingholi, M.A.; Rostami-Nejad, M.; Barzegar, F.; Rostami, K.; Volta, U.; Sadeghi, A.; Honarkar, Z.; Salehi, N.; Asadzadeh-Aghdaei, H.; Baghestani, A.R.; et al. Economic burden made celiac disease an expensive and challenging condition for Iranian patients. Gastroenterol. Hepatol. Bed Bench 2017, 10, $258-262$.

144. Mogul, D.; Nakamura, Y.; Seo, J.; Blauvelt, B.; Bridges, J.F. The unknown burden and cost of celiac disease in the U.S. Expert Rev. Pharm. Outcomes Res. 2017, 17, 181-188. [CrossRef]

145. Ross, A.C. The 2011 report on dietary reference intakes for calcium and vitamin D. Public Health Nutr. 2011, 14, 938-939. [CrossRef]

146. Holick, M.F.; Binkley, N.C.; Bischoff-Ferrari, H.A.; Gordon, C.M.; Hanley, D.A.; Heaney, R.P.; Murad, M.H.; Weaver, C.M.; Endocrine, S. Evaluation, treatment, and prevention of vitamin D deficiency: An Endocrine Society clinical practice guideline. J. Clin. Endocrinol. Metab. 2011, 96, 1911-1930. [CrossRef] 
147. Bouillon, R.; Van Schoor, N.M.; Gielen, E.; Boonen, S.; Mathieu, C.; Vanderschueren, D.; Lips, P. Optimal vitamin D status: A critical analysis on the basis of evidence-based medicine. J. Clin. Endocrinol. Metab. 2013, 98, E1283-E1304. [CrossRef]

148. Lowe, N.M.; Fekete, K.; Decsi, T. Methods of assessment of zinc status in humans: A systematic review. Am. J. Clin. Nutr. 2009, 89, 2040S-2051S. [CrossRef]

149. Nielsen, F.H.; Johnson, L.A. Data from Controlled Metabolic Ward Studies Provide Guidance for the Determination of Status Indicators and Dietary Requirements for Magnesium. Biol. Trace Elem. Res. 2017, 177, 43-52. [CrossRef]

(C) 2020 by the authors. Licensee MDPI, Basel, Switzerland. This article is an open access article distributed under the terms and conditions of the Creative Commons Attribution (CC BY) license (http://creativecommons.org/licenses/by/4.0/). 